\title{
Simulation of Moisture Adsorption by Polished Rice in Deep-Bed
}

\author{
Satoshi Murata, ${ }^{1}$ K.S.P. Amaratunga, ${ }^{1}$ Fumihiko Tanaka, ${ }^{2}$ Kazuko Shibuya, ${ }^{1}$ Shoji KoIdE $^{1}$ and \\ Toshitake UCHINO ${ }^{1}$ \\ ${ }^{1}$ Laboratory of Agricultural Process Engineering, Department of Agricultural Engineering, Faculty of Agriculture, Kyushu University, \\ Hakozaki 6-10-1, Fukuoka 812, Japan \\ ${ }^{2}$ Laboratory of Agricultural Systems Engineering, Department of Agricultural Sciences and Natural Resources, Faculty of \\ Agriculture, Kagoshima University, 1-21-24, Korimoto, Kagoshima 890, Japan
}

Received August 3, 1995

\begin{abstract}
A model was developed to predict the temperature and relative humidity of air and the temperature and moisture content of polished rice in deep-bed sorption. The model was based on one-dimensional heat and mass transfer equations with the appropriate boundary conditions and was solved using the finite difference method. Inlet temperature and inlet relative humidity were used as model inputs. For validation of the model, data were collected by ventilating the height of a $1 \mathrm{~m}$ polished rice column in a circular ( $0.14 \mathrm{~m}$ diameter) bin with moist air. Measured and predicted temperatures, relative humidity and grain moisture at different layers were in close agreement over a test period of $72 \mathrm{~h}$. Thus the model and the parameter values used are applicable for predicting moisture content in deep-bed sorption.
\end{abstract}

Keywords: adsorption, polished rice, deep-bed, moisture, simulation, model

Rewetting of low-initial-moisture polished rice was recently identified as necessary to regain the appearance, cooking and eating quality of polished rice. Aging leads to reduced moisture content if the rice is not stored under proper conditions. Moisture transfer in polished rice is rapid compared to brown and rough rice, and it is very hard to provide optimum conditions at commercial levels. So the artificial rewetting could be a good method of adding value to the low-moisture polished rice. Using normal storage bins, deepbed rewetting is a good alternative for adjusting the moisture content to a predetermined level. A thin layer sorption test was conducted to determine the basic sorption parameters of polished rice, and those data were used in the simulation model in predicting the moisture content. Muir et al. (1980) showed that a numerical method using finite differences could be used to simulate temperatures in a grain bin with fewer limitations than analytical methods. The accuracy of the finite-difference method approaches that of the analytical solution when suitable time and space increments are chosen (Yaciuk et al. 1975). Heat transfer by conduction within the grain was assumed negligible. The moist air flow was assumed uniform in the horizontal plane; that is, the flow was entirely axial and so the problem has been treated as onedimensional.

\section{Model Development}

A program was written in QBASIC to implement the model for predicting temperature, relative humidity and moisture content through deep-bed sorption. The temperature, relative humidity and grain moisture content model was based on one-dimensional heat and mass transfer equations with the associated boundary conditions and was solved using the finite difference method. In the solution approach, the grain bed was divided into a finite number of horizontal layers. There was a total of $200(\Delta y=1 / 200 \mathrm{~m})$ elements. Figure 1 shows the finite difference scheme. Each layer was subjected to uniform air and grain conditions throughout a selected time interval. The time interval was $600 \mathrm{~s}(\Delta t=600)$. Exhaust air conditions from a layer were taken as input air conditions to the layer immediately above. Knowing the inlet air conditions at any given layer and the initial layer moisture content, final air conditions and grain moisture content were calculated at the end of the selected time interval. The process was repeated for each layer in the bed at a given time interval. It was assumed that the temperature and relative humidity distribution in the grain container are uniform in the horizontal direction, that is, heat and moisture flow in the horizontal direction are negligible. At the end of each time interval, air and grain conditions were predicted during adsorption or desorption assuming that the air and grain have gone through an adiabatic process. It was also assumed that all processes are reversible and no hysteresis exists between adsorption and desorption isotherms. Several sub programs were used to calculate thermodynamic properties of moist air in a deep bed. The symbols used in this article are listed at the end of the text.

Moisture content A thin layer sorption test was conducted to calculate the necessary parameters used in this simulation. In the trial, a one-seed layer of polished rice was subjected to a stream of temperature and relative humidity controlled air $(V=360 \mathrm{~m} / \mathrm{h})$ and the moisture content was recorded with time. Air temperatures of $10,20,30$, and $40^{\circ} \mathrm{C}$, relative humidities of $50,60,70,80$ and $90 \%$, and five levels of initial moisture contents ranging approximately from $8 \%$ to $19 \%$ d.b. were used to obtain grain moisture content data. Simmonds et al. (1953) found that thin layer drying curves of 


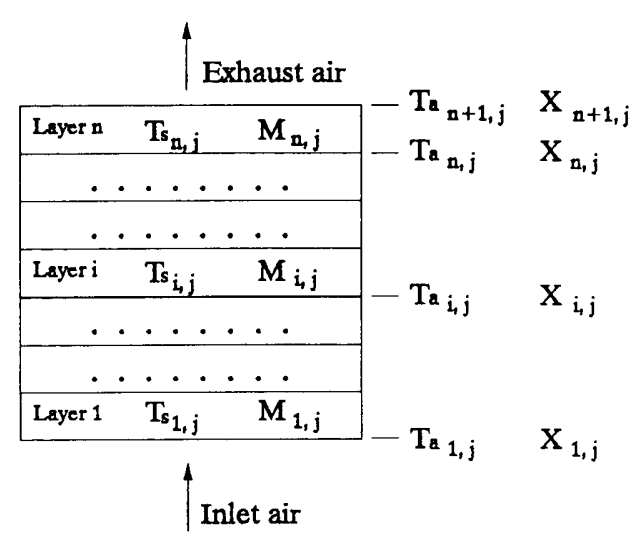

Fig. 1. Finite difference scheme.

wheat were well represented by an exponential equation, which assumed that all the resistance to moisture transfer was at the outer surface of the kernel. This equation is analogous to Newton's law of cooling, given as:

$$
\frac{\left(M-M_{\mathrm{e}}\right)}{\left(M_{0}-M_{\mathrm{e}}\right)}=\exp (-K t)
$$

Murata et al. (1993b) pointed out the equation could be applied in the case of slow adsorption or desorption process.

Using a method of nonlinear least squares, thin layer sorption data were fitted to Eq. (1) with standard deviations ranging from 0.03 to $0.32 \%$ d.b. Results revealed that the sorption coefficient $K$ varies with initial moisture. A complete set of data can be found in Murata et al. (1993a). For best fit, the initial moisture $\left(M_{0}\right)$ and sorption coefficient $(K)$ data were fitted to a third order polynomial, and the exact sorption coefficient for relevant initial moisture in the simulation model was determined. The Chen-Clayton equation (1971) as given below is used in the calculation of equilibrium moisture content, $M_{\mathrm{ed}}$.

$$
h=\exp \left\{-f_{1} T_{\mathrm{a}}{ }^{{ }_{1}} \exp \left(-f_{2} T_{\mathrm{a}}{ }^{{ }_{2}} M_{\mathrm{ed}}\right)\right\}
$$

Calculated parameter values using thin layer sorption data were as follows:

$$
\begin{aligned}
& f_{1}=2.5119 \times 10^{7}, \quad g_{1}=-2.6308 \\
& f_{2}=6.0070 \times 10^{-2}, g_{2}=1.0073
\end{aligned}
$$

Becker and Sallans (1955) suggested that the drying constant $K$ in Eq. (1) was a function of the absolute temperature of the grain, in the form of an Arrhenius equation. Murata $e t$ al. (1993a) used it to relate $K$ to the temperature of the drying air and gave the following relationship.

$$
K=\exp \left(A_{5}+\frac{A_{1}+A_{2} h+A_{3} h^{2}+A_{4} h^{3}}{T}\right)
$$

Parameter values were calculated using thin layer sorption data and were as follows:

$$
\begin{aligned}
& A_{1}=-6222.8656 \\
& A_{2}=13305.3006 \\
& A_{3}=-24418.0316 \\
& A_{4}=14007.8614 \\
& A_{5}=12.3273
\end{aligned}
$$

Latent heat of evaporation The energy required to vaporize water from a cereal grain is dependent upon its moisture content and temperature. The lower the moisture content and the temperature, the higher will be its heat of vaporization. The Clausius-Clapeyron equation (Moore, 1962) gives a relationship representing the change in saturated vapor pressure with the latent heat of vaporization as:

$$
\frac{\partial P_{\mathrm{st}}}{\partial T}=\frac{q}{T\left(V_{\mathrm{g}}-V_{1}\right)}
$$

By rearranging Eq. (4) we get

$$
q=\left(V_{\mathrm{g}}-V_{1}\right) T\left(\frac{\partial P_{\mathrm{st}}}{\partial T}\right)
$$

The vapor pressure in polished rice $\left(P_{\mathrm{st}}\right)$ is calculated using the following equation.

$$
P_{\mathrm{st}}=h P_{\mathrm{s}}
$$

Equilibrium relative humidity $(h)$ is calculated using the Chen-Clayton equation, Eq. (2). The saturated vapor pressure $\left(P_{\mathrm{S}}\right)$ and the specific volume of the water vapor $\left(V_{\mathrm{g}}\right)$ are calculated using equations given in the IFC Formulation for Industrial Use (JSME, 1980).

$\partial P_{\text {st }} / \partial T$ in Eq. (5) is obtained by differentiating Eq. (6) with respect to $T$ given by

$$
\frac{\partial P_{\mathrm{st}}}{\partial T}=\frac{\partial h}{\partial T} P_{\mathrm{s}}+\frac{\partial P_{\mathrm{s}}}{\partial T} h
$$

The term $\partial h / \partial T$ in the above equation is given by differentiating the Chen-Clayton equation (Eq. (2)) with respect to $T$ as follows:

$$
\begin{aligned}
\frac{\partial h}{\partial T}= & -h \exp \left(-f_{2} T^{g_{2}} M_{\mathrm{ed}}\right) \\
& \times\left(f_{1} g_{1} T^{\left(g_{1}-1\right)}-f_{1} f_{2} g_{2} T^{\left(g_{1}+g_{2}-1\right)} M_{\mathrm{ed}}\right)
\end{aligned}
$$

Using the above calculation procedure, the heat of absorbed water $q$ was calculated. This is equal to the latent heat of evaporation of water in polished rice, $\sigma$.

Simulation The program flowchart is shown in Fig. 2. There are several subroutines in the program to calculate the equilibrium moisture content $\left(M_{\mathrm{e}}\right)$, sorption coefficient $(K)$, heat of absorbed water $(q)$, and thermodynamic properties of moist air. The moisture content is calculated using the following differential equation derived from Eq. (1) given as:

$$
\frac{d M}{d t}=-K\left(M-M_{\mathrm{e}}\right)
$$

for the initial condition $M=M_{0}$ when $t=0$.

The following differential equation is used to calculate the temperature of polished rice.

$$
\frac{\partial T_{\mathrm{s}}}{\partial t}=\left(\frac{h_{\mathrm{a}}}{C_{\mathrm{ps}} \rho_{\mathrm{s}}}\right)\left(T_{\mathrm{a}}-T_{\mathrm{s}}\right)-\left(\frac{K q}{C_{\mathrm{ps}}}\right) \frac{M-M_{\mathrm{e}}}{100}
$$

The heat-transfer coefficient of this equation $\left(h_{\mathrm{a}}\right)$ is calculated by employing the method given in Barker (1965) as:

$$
h_{\mathrm{a}}=22.884 G^{0.6} \quad\left(\mathrm{~kJ} / \mathrm{min} \cdot \mathrm{m}^{2} \cdot \mathrm{K} \text { of polished rice }\right)
$$

The bulk density of polished rice $\left(\rho_{\mathrm{s}}\right)$ at the moisture content of $14 \%$ d.b. was $912 \mathrm{~kg} / \mathrm{m}^{3}$. The sorption coefficient $(K)$ is calculated using Eq. (3), and the specific heat of polished rice $\left(C_{\mathrm{ps}}\right)$ is determined using the following equation (Murata et al., 1987).

$$
C_{\mathrm{ps}}=0.921+4.1868 M_{\mathrm{d}}
$$

Absolute humidity is calculated as: 


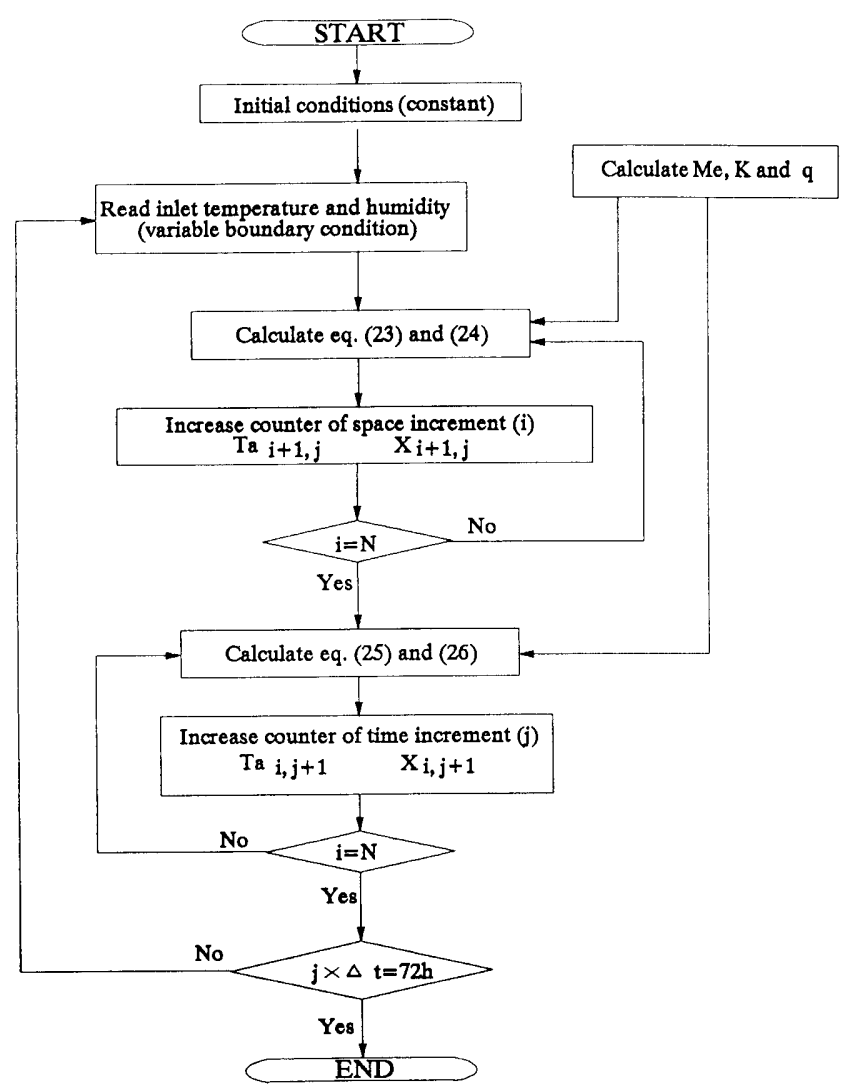

Fig. 2. Program flowchart for predicting moisture content.

$$
\frac{\partial X}{\partial y}=-K_{2}\left(M-M_{\mathrm{e}}\right) / 100
$$

Where:

$$
\begin{gathered}
K_{2}=\rho_{\mathrm{s}} \frac{K}{G} \\
G=V_{\rho_{\mathrm{a}}} \quad\left(\mathrm{kgf} / \mathrm{m}^{2}\right) \\
\rho_{\mathrm{a}}=\frac{353.3}{T_{\mathrm{a}}} \quad\left(\mathrm{kgf} / \mathrm{m}^{3}\right)
\end{gathered}
$$

The enthalpy of air is calculated as:

$$
\frac{\partial I}{\partial y}=\left(\sigma K_{2}\right)\left(M-M_{\mathrm{e}}\right)-\left(\frac{h_{\mathrm{a}}}{G}\right)\left(T_{\mathrm{a}}-T_{\mathrm{s}}\right)
$$

Where $\sigma$, the latent heat of vaporization of water in polished rice, is calculated as shown in the preceding section.

Using this enthalpy, the temperature of air is calculated as follows:

$$
T_{\mathrm{a}}=\left(\frac{I-\sigma X}{C_{\mathrm{pa}}+C_{\mathrm{pw}} X}\right)
$$

The relative humidity of air leaving the layer is calculated as:

$$
h=\frac{p}{P_{\mathrm{S}}}
$$

Where:

$$
P_{\mathrm{s}}=P_{\mathrm{s}}\left(T_{\mathrm{a}}\right)
$$

and

$$
p=\frac{P X}{0.622+X}
$$

Atmospheric pressure $(P)$ is taken as $101.325 \mathrm{kPa}$, while $P_{\mathrm{s}}$ was calculated according to the procedures given in the IFC Formulation for Industrial Use (JSME, 1980).

The equilibrium moisture content is calculated using the Chen-Clayton equation Eq. (2). The heat of absorbed water is calculated using the following equation.

$$
q=\left(V_{\mathrm{g}}-V_{1}\right) T\left(\frac{\partial P_{\mathrm{st}}}{\partial T}\right)
$$

Where:

$$
\left(V_{\mathrm{g}}-V_{1}\right)=R_{\mathrm{w}} \frac{T}{p}-0.001
$$

The gas constant of water vapor $\left(R_{\mathrm{w}}\right)$ is taken as 0.461917 $\mathrm{kJ} / \mathrm{kgf} \cdot \mathrm{K}$ (Cengel \& Boles, 1989).

$\partial P_{\text {st }} / \partial T$ is calculated by differentiating the Chen-Clayton equation with respect to $T$ given by:

$$
\begin{aligned}
\frac{\partial h}{\partial T}= & -h \exp \left(-f_{2} T^{g_{2}} M\right)\left\{f_{1} g_{1} T^{\left(g_{1}-1\right)}\right. \\
& \left.-f_{1} f_{2} g_{2} T^{\left(g_{1}+g_{2}-1\right)} M\right\}
\end{aligned}
$$

Using Eq. (12), the expression for predicting absolute humidity $\left(\mathrm{kg}-\mathrm{H}_{2} \mathrm{O} / \mathrm{kg}\right.$-dry air) written in the finite difference form is given by:

$$
X_{i+1, j}=X_{i, j}+K_{2}\left(M_{i, j}-M_{\mathrm{e}_{i, j}}\right) \Delta L
$$

Similarly, using Eq. (16), the enthalpy of air $(\mathrm{kJ} / \mathrm{kg}$-dry air) can be written as:

$$
I_{i+1, j}=I_{i, j}+\left(\sigma K_{2}\right)\left(M_{i, j}-M_{\mathrm{e}_{i, j}}\right) \Delta L-\left(\frac{h_{\mathrm{a}}}{G}\right)\left(T_{\mathrm{a}_{i, j}}-T_{\mathrm{s}_{i, j}}\right) \Delta L
$$

Using Eq. (9), the following finite difference form equation is used to calculate the moisture content $\left(M_{i}\right)$ of polished rice.

$$
M_{i, j+1}=M_{i, j}-K\left(M_{i, j}-M_{\mathrm{e}_{i, j}}\right) \Delta t
$$

The temperature of polished rice is calculated using the following equation.

$$
\begin{aligned}
T_{\mathrm{s}_{i, j+1}}=T_{\mathrm{s}_{i, j}} & +\left(\frac{h_{\mathrm{a}}}{C_{\mathrm{ps}} \rho}\right)\left(T_{\mathrm{a}_{i, j}}-T_{\mathrm{s}_{i, j}}\right) \Delta t \\
& -\left(\frac{K q}{C_{\mathrm{ps}}}\right)\left(M_{i, j}-M_{\mathrm{e}_{i, j}}\right) \Delta t
\end{aligned}
$$

In the model,

$$
\Delta L \text { (element thickness) }=0.005 \mathrm{~m}
$$

and

$$
\Delta t \text { (time increment })=600 \mathrm{~s}
$$

Initial and boundary conditions are as follows:

$$
\begin{aligned}
& \text { I.C. }=\left\{\begin{aligned}
T_{\mathrm{s}_{i, 0}}= & \text { Temperature of rice at the beginning } \\
M_{\mathrm{s}_{i, 0}}= & \text { Moisture content of polished rice at the } \\
& \text { beginning }
\end{aligned}\right. \\
& \text { B.C. }=\left\{\begin{aligned}
& T_{\mathrm{a}_{1, j}}= \text { Inlet temperature of air from observed data } \\
& X_{\mathrm{a}_{1, j}}= \text { Inlet relative humidity of air from observed } \\
& \text { data }
\end{aligned}\right.
\end{aligned}
$$

\section{Validation of the Model}

The numerical model of heat and moisture transport developed in the previous section is applied to the following sorption test.

Materials The variety of rice was Hinohikari harvested in Fukuoka during October 1994. Moisture content of unpolished rice at the time of buying was $19 \%$ d.b. The rice was polished to a polishing degree of $90 \%$ and allowed to dry in the laboratory roughly for one week until the moisture 


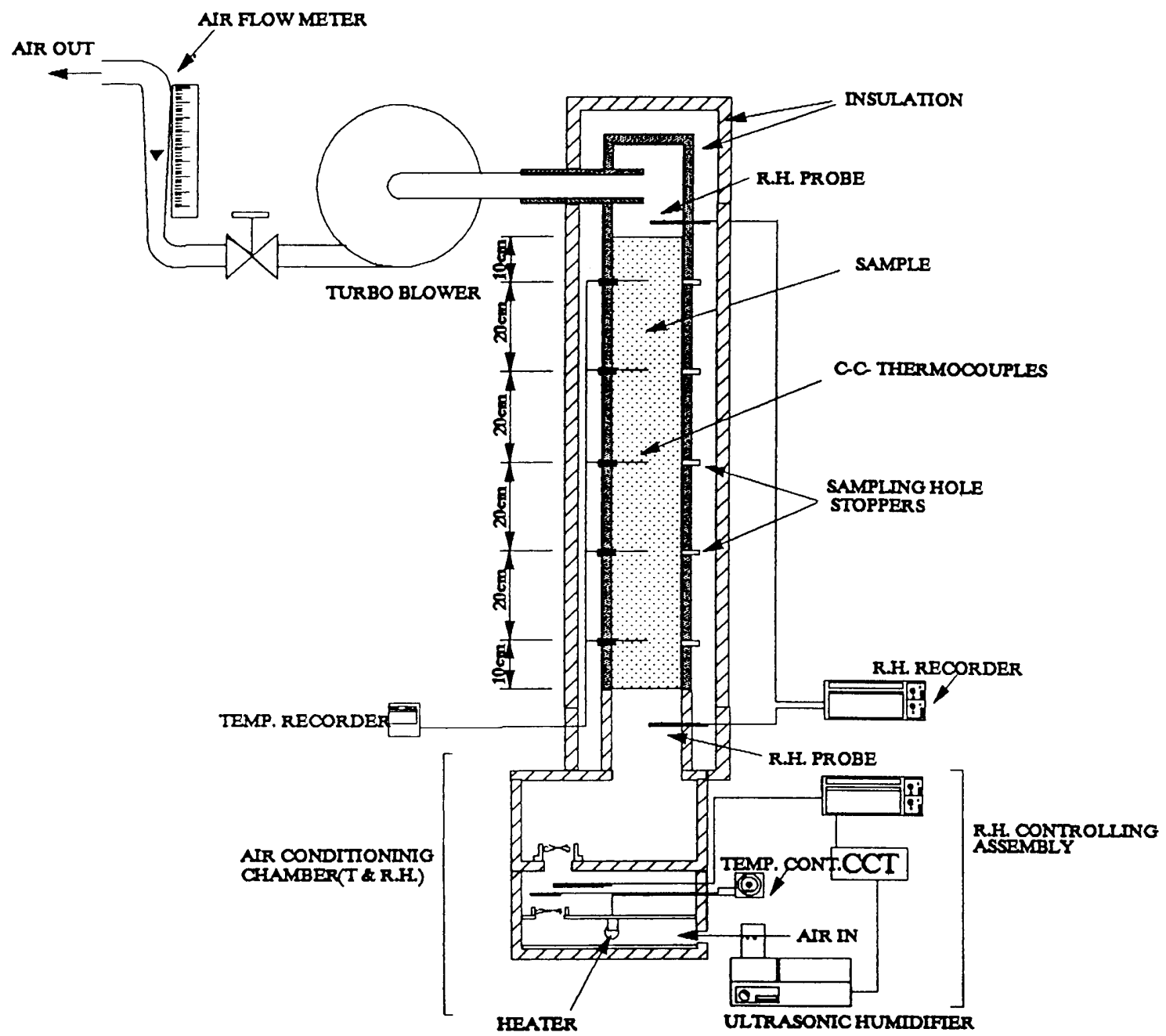

Fig. 3. Schematic diagram of the experimental apparatus.

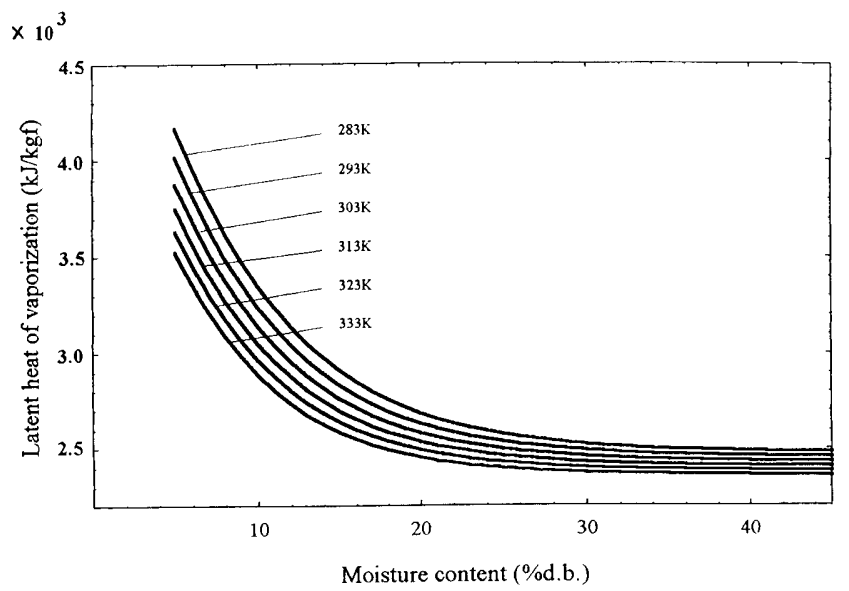

Fig. 4. Latent heat of vaporization of water in polished rice at different temperatures.

content reached $15 \%$ d.b. The bulk sample was stored at $5^{\circ} \mathrm{C}$ storage until the time for the tests. Before the sample was placed in the experimental apparatus (Fig. 3), the temperature of the rice was brought to room temperature by keeping it in an air-sealed container for $24 \mathrm{~h}$.

Experimental set-up and procedure The experimental apparatus is illustrated in Fig. 3. Polished rice was placed in a $0.14 \mathrm{~m}$ diameter PVC (0.004 $\mathrm{m}$ thick) circular pipe up to 1 $\mathrm{m}$ height. The sorption test was conducted for $72 \mathrm{~h}$ by ventilating the temperature and relative humidity controlled air. With the use of an ultrasonic humidifier, sensors and control devices, the relative humidity was brought near $80 \%$.

The temperature of the air at the inlet, at 0.1, 0.3, 0.5, 0.7, $0.9 \mathrm{~m}$ layers in the sample and at the outlet was measured using c-c thermocouples and was recorded continuously throughout the test. The relative humidity of the air was measured at the inlet and outlet using R.H. sensors (VAISALA HMP115Y) and recorded continuously during the entire testing period. The moisture content was measured using $5 \mathrm{~g}$ samples, drawn at predetermined time intervals $(0$, $1,2,3,4,5,6,7,9,12,18,24,36,48$ and $72 \mathrm{~h}$ ) from the $0.1,0.3$, $0.5,0.7,0.9 \mathrm{~m}$ layers by an air-oven method $\left(135^{\circ} \mathrm{C}\right.$ for $\left.24 \mathrm{~h}\right)$.

\section{Results}

Figure 4 shows the latent heat of vaporization (LHV) isotherms calculated using the Clausius-Clapeyron equation Eq. (4). This shows that the LHV depends on the temperature and moisture content. The higher the temperature and grain moisture, the lower the LHV. The value of the LHV approaches the LHV of free water at moisture contents higher than $40 \%$ d.b. Decreasing moisture below $10 \%$ d.b. increases the LHV almost exponentially. This is because water is 


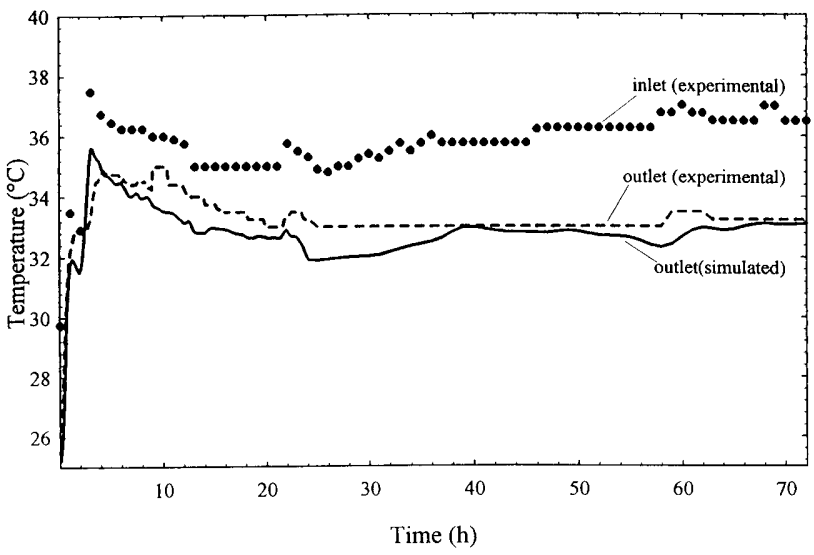

Fig. 5. Simulated outlet temperature of air and the experimental temperatures of air at the inlet and outlet.

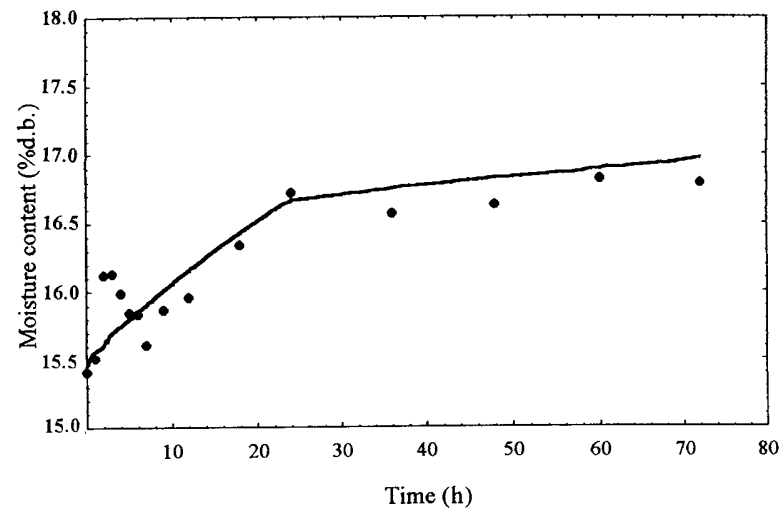

Fig. 7. Comparison of observed (symbols) and model-computed (line) grain moisture content at $0.1 \mathrm{~m}$ from the bottom of the rice column.

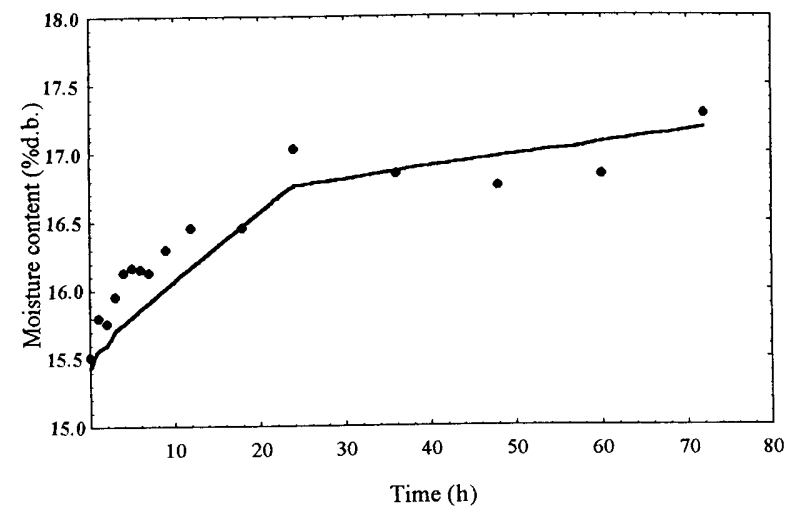

Fig. 9. Comparison of observed (symbols) and model-computed (line) grain moisture content at the middle ( $0.5 \mathrm{~m}$ from the bottom) of the rice column.

bound at lower moisture contents.

Figure 5 shows the model-computed outlet temperature of the air and the experimental temperatures of the air at the inlet and outlet. The model predictions of air temperature closely matched the observed values throughout the entire sorption period with the difference normally less than $1.5^{\circ} \mathrm{C}$. The standard error in the estimated outlet air temperature was

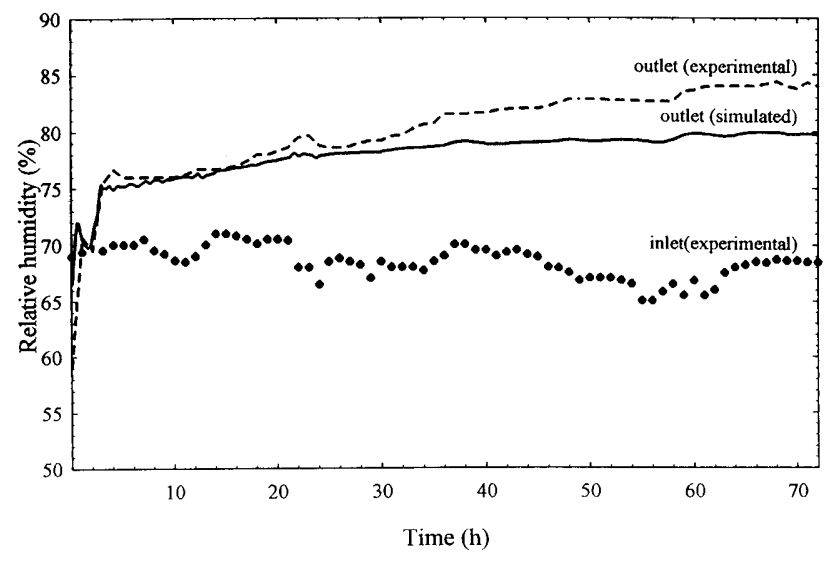

Fig. 6. Simulated outlet relative humidity of air and the experimental relative humidity of air at the inlet and outlet.

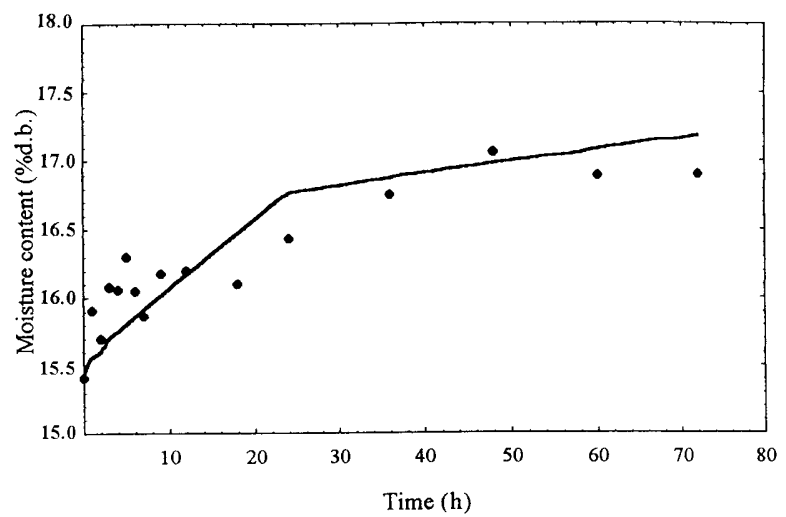

Fig. 8. Comparison of observed (symbols) and model-computed (line) grain moisture content at $0.3 \mathrm{~m}$ from the bottom of the rice column.

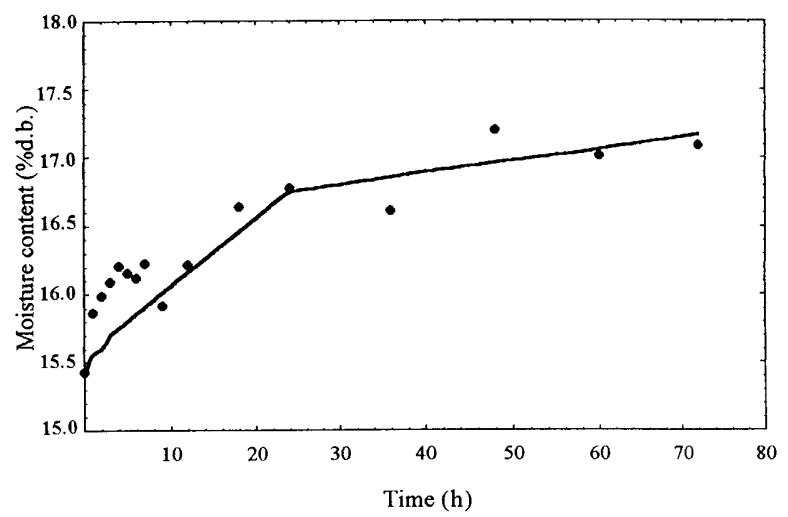

Fig. 10. Comparison of observed (symbols) and model-computed (line) grain moisture content at $0.7 \mathrm{~m}$ from the bottom of the rice column.

$0.794^{\circ} \mathrm{C}$. Because the reverse process of evaporation, which takes place during sorption, is accompanied by the release of the LHV, the predicted temperature of the rice grains was slightly higher than the temperature of the air. The average temperature difference of the air and rice grains was $0.133^{\circ} \mathrm{C}$.

The predicted outlet relative humidity closely followed the measured value and was slightly lower than that observed 


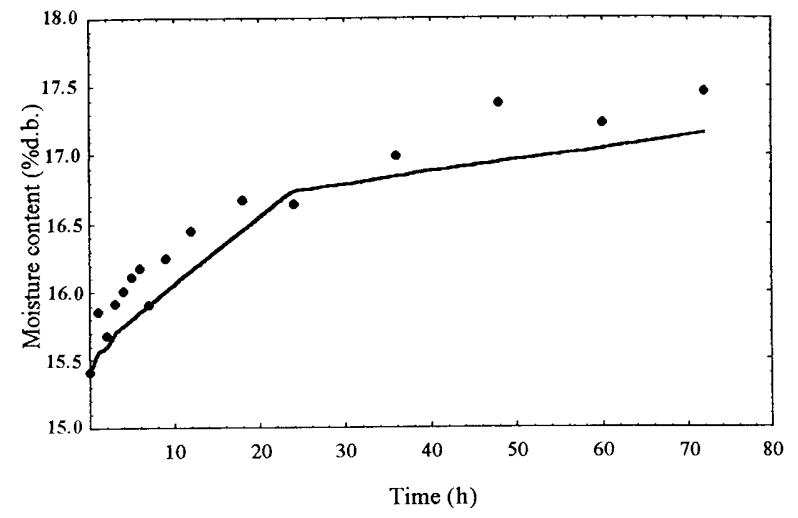

Fig. 11. Comparison of observed (symbols) and model-computed (line) grain moisture content at $0.9 \mathrm{~m}$ from the bottom of the rice column.

after $14 \mathrm{~h}$. The average absolute prediction error over the entire sorption period of $72 \mathrm{~h}$ was 1.02 percentage points. Figure 6 shows the simulated outlet relative humidity of the air and the experimental relative humidity of the air at the inlet and outlet. The standard error in the estimated relative humidity at the outlet for $72 \mathrm{~h}$ sorption was $1.91 \%$. The method used in measuring the relative humidity produced a $2 \%$ error. The other major experimental error was the atmospheric air leaking into the sorption bin when the stoppers were opened to remove rice samples for moisture determination.

Model-predicted moisture contents of polished rice at each layer were compared with the observed data. Standard errors were $0.49,0.42,0.3,0.31,0.37 \%$ d.b. for the $0.1,0.3,0.5,0.7$ and $0.9 \mathrm{~m}$ layer respectively. Figures 7 through 11 show the observed and model-computed grain moisture contents at the $0.1,0.3,0.5,0.7$ and $0.9 \mathrm{~m}$ layers. The measuring error in the moisture content using $5 \mathrm{~g}$ samples was $0.148 \%$ d.b.

\section{Conclusions}

A dimensional heat and mass transfer model has been developed to predict the moisture content in the deep-bed sorption of polished rice. Predicted moisture contents closely matched the observed values with differences of less than 0.97 percentage point. The model predicted temperature and relative humidity of air compared reasonably well with the observed values. The standard errors in the estimated temperature and relative humidity at the outlet were $0.794^{\circ} \mathrm{C}$ and $1.91 \%$ R.H. respectively. As indicated by the simulation results, parameter values used in the model are applicable for predicting moisture content, temperature and relative humidity in deep-bed sorption.

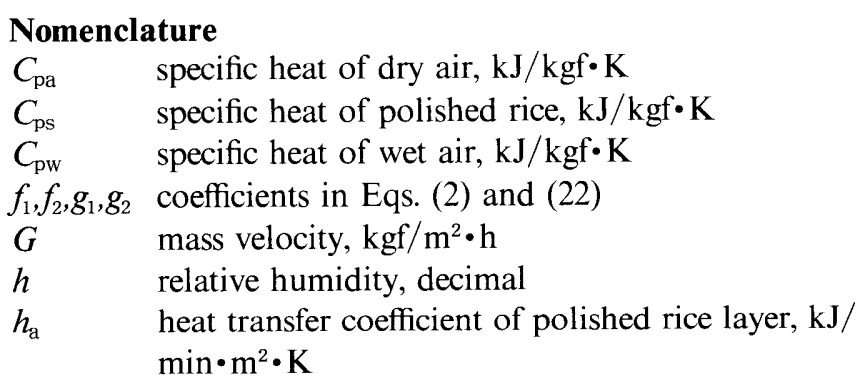

\section{References}

Barker, J.J. (1965). Heat transfer of beds. Ind. Eng. Chem., 57(4), 4351.

Becker, H.A. and Sallans, H.R. (1955). A study of internal moisture movement in the drying of the wheat kernel. Cereal Chem., 32(May), 212-226.

Cengel, Y.A. and Boles, M.A. (1989). Molar mass, gas constant, and critical-point properties. In "Thermodynamics an Engineering Approach," 2nd Ed., McGraw-Hill, p. 868.

Chen, C.S. and Clayton, J.T. (1971). The effect of temperature on sorption isotherms of biological materials. Trans. ASAE, 14, 927929.

Moore, W.J. (1962). "Physical Chemistry," 3rd Ed., Prentice-Hall, Englewood Cliffs, N.J., p. 27.

Muir, W.E., Fraser, M. and Sinha, R.N. (1980). Simulation model of two-dimensional heat transfer in controlled-atmosphere grain bins. In "Controlled Atmosphere Storage of Grain," ed. by J. Shejbal, Amsterdam, Elsevier Scientific Publ. Co., pp. 385-398.

Murata, S., Tagawa, A. and Ishibashi, S. (1987). The effect of moisture content and temperature on specific heat of cereal grains measured by DSC. J. Jpn. Soc. Agric. Mach., 46, 547-554.

Murata, S., Amaratunga, K.S.P., Tanaka, F. and Hori, Y. (1993a). Effect of initial moisture on the adsorption and desorption equilibrium moisture contents of polished rice. J. Fac. Agric., Kyushu Univ., 38, 161-173.

Murata, S., Enomoto, T. and Miyauchi, K. (1993b). Adsorption characteristics of thin silica-gel layer and simulation in the fixed layer. J. Jpn. Soc. Agric. Mach., 55(3), 41-49.

Simmonds, W.H.C., Ward, G.T. and McEwen, E. (1953). The drying of wheat grain Part I: The mechanism of drying. Trans. Inst. Chem. Eng., 31, 265-278.

The Japan Society of Mechanical Engineers (1980). International Formulation Committee of Sixth International Conference on the Properties of Steam. IFC formulation for industrial use (1967). SI JSME Steam Tables, pp. 106-119.

Yaciuk, G., Muir, W.E. and Sinha, R.N. (1975). A simulation model of temperatures in stored grain. J. Agric. Eng. Res., 20, 245-258. 